\title{
INTEGRAL INEQUALITIES AND THEIR APPLICATIONS TO THE CALCULUS OF VARIATIONS ON TIME SCALES
}

\author{
Martin J. Bohner, Rui A. C. Ferreira And Delfim F. M. Torres
}

Abstract. We discuss the use of inequalities to obtain the solution of certain variational problems on time scales.

Mathematics subject classification (2010): 26D15, 49K05, 39A10.

Keywords and phrases: Time scales, calculus of variations, optimal control, integral inequalities, Jensen's inequality, global minimizers.

\section{REFERENCES}

[1] R. Agarwal, M. Bohner And A. Peterson, Inequalities on time scales: a survey, Math. Inequal. Appl., 4, 4 (2001), 535-557.

[2] F. M. Atici, D. C. Biles And A. Lebedinsky, An application of time scales to economics, Math. Comput. Modelling, 43, 7-8 (2006), 718-726.

[3] Z. BartosiewicZ And D. F. M. Torres, Noether's theorem on time scales, J. Math. Anal. Appl., 342, 2 (2008), 1220-1226.

[4] M. Bohner, Calculus of variations on time scales, Dynam. Systems Appl., 13, 3-4 (2004), 339-349.

[5] M. Bohner And T. Matthews, Ostrowski inequalities on time scales, JIPAM. J. Inequal. Pure Appl. Math., 9, 1 (2008), Article 6, 8 pp.

[6] M. Bohner And A. Peterson, Dynamic equations on time scales, Birkhäuser Boston, Boston, MA, 2001.

[7] M. Bohner And A. Peterson, Advances in dynamic equations on time scales, Birkhäuser Boston, Boston, MA, 2003.

[8] W.-S. Cheung, Integral inequalities and applications to the calculus of variations, Int. J. Appl. Math., 9, 1 (2002), 85-108.

[9] O. Dunkel, Integral Inequalities With Applications to the Calculus of Variations, Amer. Math. Monthly, 31, 7 (1924), 326-337.

[10] R. A. C. Ferreira, M. R. Sidi Ammi And D. F. M. Torres, Diamond-alpha integral inequalities on time scales, Int. J. Math. Stat., 5, A09 (2009), 52-59.

[11] R. A. C. Ferreira AND D. F. M. Torres, Remarks on the calculus of variations on time scales, Int. J. Ecol. Econ. Stat., 9, F07 (2007), 65-73.

[12] R. A. C. FERREIRA AND D. F. M. TORRES, Higher-order calculus of variations on time scales, in Mathematical Control Theory and Finance, Springer, 2008, 149-159.

[13] R. A. C. Ferreira AND D. F. M. TORRES, Generalizations of Gronwall-Bihari inequalities on time scales, J. Difference Equ. Appl., 15, 6 (2009), 529-539.

[14] R. A. C. FERREIRA AND D. F. M. TORRES, Isoperimetric problems of the calculus of variations on time scales, Contemporary Mathematics (2010), in press.

[15] G. H. Hardy, J. E. LitTlewood, Some integral inequalities connected with the calculus of variations, Q. J. Math., Oxf. Ser., 3 (1932), 241-252.

[16] G. H. Hardy, J. E. Littlewood and G. Pólya, Inequalities, 2nd ed., Cambridge University Press, 1952.

[17] S. Hilger, Analysis on measure chains-a unified approach to continuous and discrete calculus, Results Math., 18, 1-2 (1990), 18-56.

[18] S. HILGER, Differential and difference calculus—unified!, Nonlinear Anal., 30, 5 (1997), 2683-2694. 
[19] R. Hilscher AND V. Zeidan, Calculus of variations on time scales: weak local piecewise $C_{\mathrm{rd}}^{1}$ solutions with variable endpoints, J. Math. Anal. Appl., 289, 1 (2004), 143-166.

[20] A. B. Malinowska AND D. F. M. TorRes, Necessary and sufficient conditions for local Pareto optimality on time scales, J. Math. Sci. (N. Y.), 161, 6 (2009), 803-810.

[21] C. Sbordone, On some integral inequalities and their applications to the calculus of variations, Boll. Un. Mat. Ital. C (6), 5, 1 (1986), 73-94.

[22] M. R. Sidi Ammi, R. A. C. Ferreira AND D. F. M. Torres, Diamond- $\alpha$ Jensen's inequality on time scales, J. Inequal. Appl., 2008, Art. ID 576876, 13 pp.

[23] M. R. Sidi Ammi AND D. F. M. Torres, Combined dynamic Grüss inequalities on time scales, J. Math. Sci. (N. Y.), 161, 6 (2009), 792-802.

[24] F.-H. Wong, C.-C. YeH AND W.-C. LiAn, An extension of Jensen's inequality on time scales, Adv. Dyn. Syst. Appl., 1, 1 (2006), 113-120. 